\title{
Görme Bozukluğu ve Baş Ağrısı ile Başvuran Hastada Dev Araknoid Kist Olgusu
}

\author{
Giant Arachnoid Cyst in a Patient Presenting with Visual Impairment and Headache
}

Serkan KIRIK ${ }^{1}$, Olcay GÜNGÖR ${ }^{1}$, Sedat IŞIKAY ${ }^{2}$, Yasemin ÇOBAN ${ }^{3}$, Yasemin KIRIK ${ }^{4}$

${ }^{1}$ Uzman Dr, Kahramanmaraş Sütçü İmam Üniversitesi Tip Fakültesi Çocuk Nöroloji BD, KAHRAMANMARAŞ
${ }^{2}$ Doç. Dr, Kahramanmaraş Sütçü İmam Üniversitesi Tip Fakültesi Çocuk Nöroloji BD, KAHRAMANMARAŞ
${ }^{3}$ Uzman Dr, Kahramanmaraş Sütçü İmam Üniversitesi Tip Fakültesi, Çocuk Yoğun Bakım BD, KAHRAMANMARAŞ
${ }^{4}$ Uzman Dr, Necip Fazıl Şehir Hastanesi, Enfeksiyon Hastalıkları ve Klinik Mikrobiyoloji Kliniği, KAHRAMANMARAŞ

\section{Özet}

Araknoid kistler, beyin veya omurilik ile araknoid membran arasında bulunan, iyi huylu, beyin omurilik sıvısı dolu keseciklerdir. Genellikle araknoid kistler, beyin görüntülemesinde tesadüfen saptanırlar, ancak bazen genişleme veya kanama nedeniyle semptomlara neden olabilirler. Bu yazıda son 1 yıldır giderek artan baş ağrısı ve eşlik eden görme bulanıklığı tarif eden 16 yaşında erkek hasta sunulmuştur.

Anahtar Kelimeler: Araknoid kist, baş ağrısı, görme bozukluğu

\section{Abstract}

Arachnoid cysts are benign cerebrospinal fluid-filled sacs located between the brain or spinal cord and the arachnoid membrane. Arachnoid cysts are generally identified incidentally on brain imaging, however they may occasionally cause symptoms because of bleeding or expansion. In this study, a 16- year-old male, increasing headache and accompanying blurred vision during the last 1 year was presented.

Key Words: Music, Physiology, Brain, Epilepsy, Therapy.

\section{GİRIŞ}

Araknoid kistler benign, non-neoplastik serebrospinal sıvı içeren lezyondur; Çoğu zaman sessiz kliniğe sahiptirler ve takip eden süreçte boyutları değişmemiştir (1). Daha önceki çalışmalarda araknoid kistlerin görülme sıklığının \% 0,3 ile \% 1,7 arasında olduğu bildirilmiştir (2). Bununla birlikte, ileri nörogörüntüleme teknikleri araknoid kistlerin teşhisini kolaylaştırmış ve bu da araknoid kistlerde tespit edilen vakaların sayısının artmasına neden olmuştur (3).

Bazı vakalarda araknoid kist semptomatik hale gelir ve ortaya çıkan klinik kistin büyüklüğüne ve yerine göre değişir. En sik rastlanan semptom, başlıca baş ağrısıdır; bu, lokal kitle etkisi, intrakraniyal basıncın artması ve / veya hidrosefali nedeniyle oluşur. Ek olarak nöbetler, kognitif bozukluk, görme kaybi/bozukluğu ve intrakraniyal hemoraji ortaya çıkabilir $(3,4)$.

$\mathrm{Bu}$ yazıda sağ temporalde araknoid kisti olan 1 yıldır medikal tedaviye dirençli baş ağrısı ve eşlik eden görme bulanıklığı olan 16 yaşındaki erkek hasta sunulmuştur.

\section{OLGU SUNUMU}

Çocuk nöroloji polikliniğimize görmede bulanıklaşma ve 1 yıldır artan baş ağrısı şikâyeti tarifleyen 16 yaşındaki erkek hasta başvurdu. Anamnezi sorgulandığında 1yıldır giderek artan ve flunarizin hidroklorür, topiramat gibi çeşitli medikal tedavilere yanıt vermeyen baş ağrısı belirtti. Baş ağrılarına ek olarak eş zamanlı görme bulanıklı̆̆ ifade ediyordu. Bunların haricinde 10 gün önce $2 \mathrm{kez}$ olan senkop atağ

$\begin{array}{ll}\text { İletişim: } & \begin{array}{l}\text { Dr. Serkan Kırık, Kahramanmaraş Sütçü İmam Üniver- } \\ \text { sitesi Tip Fakültesi Çocuk Nöroloji Bilim Dalı, KAHRA- } \\ \text { MANMARAŞ }\end{array} \\ \text { DOI: } & \mathbf{1 0 . 1 7 5 1 7 / k s u t f d . 3 2 1 8 5 4}\end{array}$

tarif ediyordu. Nörolojik muayenesi doğaldı. Psikomotor gelişimi normaldi. Laboratuvar değerlerinde özellik tespit edilmedi. Bakilan optik koherans tomografide (OCT) sağ temporalde minimal görme alanı defekti saptandı. Göz dibi ve fundus muayenesi doğaldı. Bayılma öyküsü olması üzerine yapılan kardiyolojik değerlendirmesi normaldi. Elektroensefalogram (EEG) incelemesinde epileptik anormallik saptanmadi. Manyetik rezonans görüntülemesinde (MRG) sağ temporalde $4 \times 4 \mathrm{~cm}$ araknoid kistle uyumlu görünüm saptandı (Resim-1, Resim-2). Beyin cerrahisi kliniği ile konsülte edilen hastaya cerrahi rezeksiyon önerildi. Cerrahi operasyonla alınan kitlenin histopatolajik incelemesi araknoid kist ile uyumlu olarak değerlendirildi. Cerrahi rezeksiyon ile hastanın mevcut şikâyetleri 3 ay sonraki kontrolünde gerilemişti.

\section{TARTIŞMA}

Araknoid kistler iyi huylu, non-neoplastik ve ekstra-aksiyel lezyonlardır. Prevalansı yaklaşık olarak tüm intrakraniyal kitle lezyonlarının \% 1'i kadardır; buna karşın bilgisayarlı tomografi (BT) ve MRG tekniklerinin kullanımının yaygınlaşmasıyla tespit edilen vakaların sayısı artmıştır (1, 3). Kraniyal fossadaki kistler, erkeklerde ve sol tarafta daha sik olarak bulunurlar. Daha çok santral sinir sistemi gelişimsel anomalisi şeklinde ortaya çıkarlar ve rastlantısal olarak tespit edilirler $(1,4)$.

Al-Holou ve ark., 48417 beyin görüntüsünü gözden geçirmiş ve $661(\%$ 1.4) hastada araknoid kist tespit etmiştir. Bu çalışmada, araknoid kist prevalansı

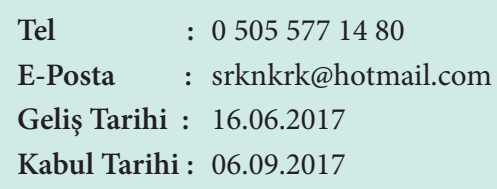


çocuklarda (\% 2.6), yetișkinlerden biraz daha yüksekti. Erkeklerde (\% 1.8) kadınlardan (\% 1.1) daha yüksek bir prevalansa sahiptir $(1,5)$. En s1k görülen yerler orta fossa (\% 34), retroserebellar bölge (\% 33) ve serebral konveksitedir (\% 14). Buna karşın neden büyüdükleri ve bunun mekanizması henüz tam olarak aydınlatılamamıştır $(5,6)$.

Resim-1: T1 kesitte sağ temporal bölgede dev araknoid kistin görünümü

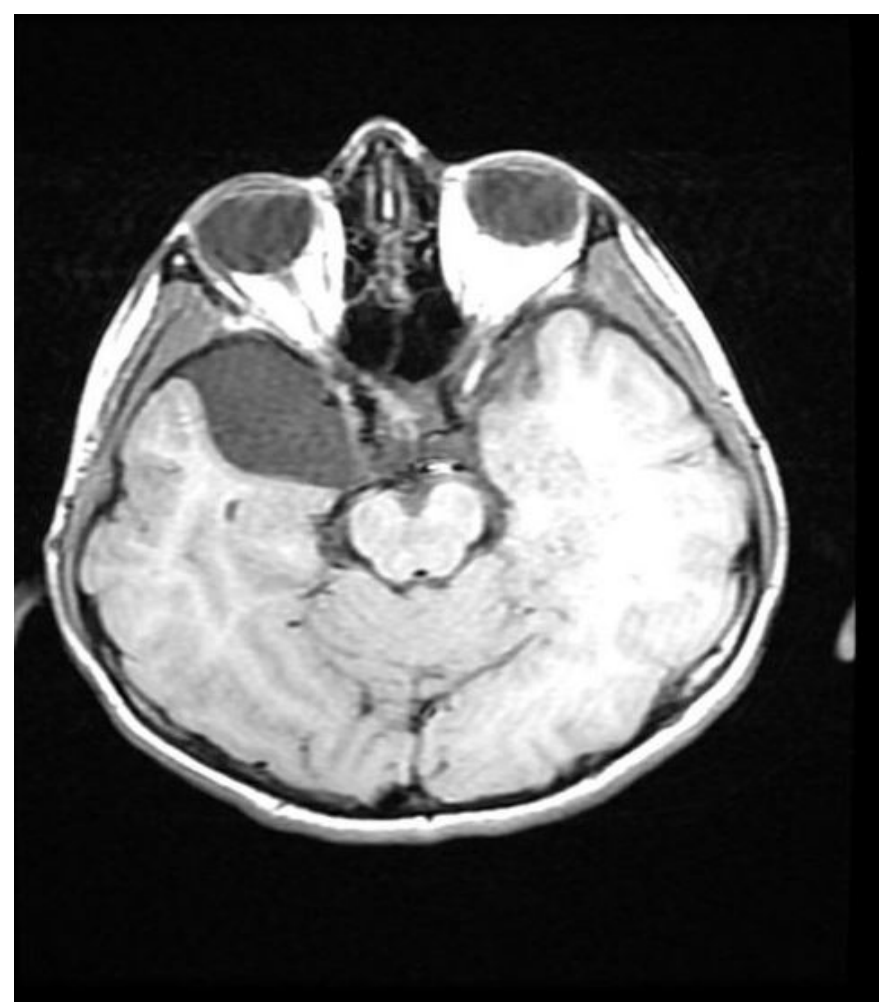

Resim-2: T2 kesitte sağ temporal bölgede araknoid kistin görünümü ve optik sinire komşuluğu

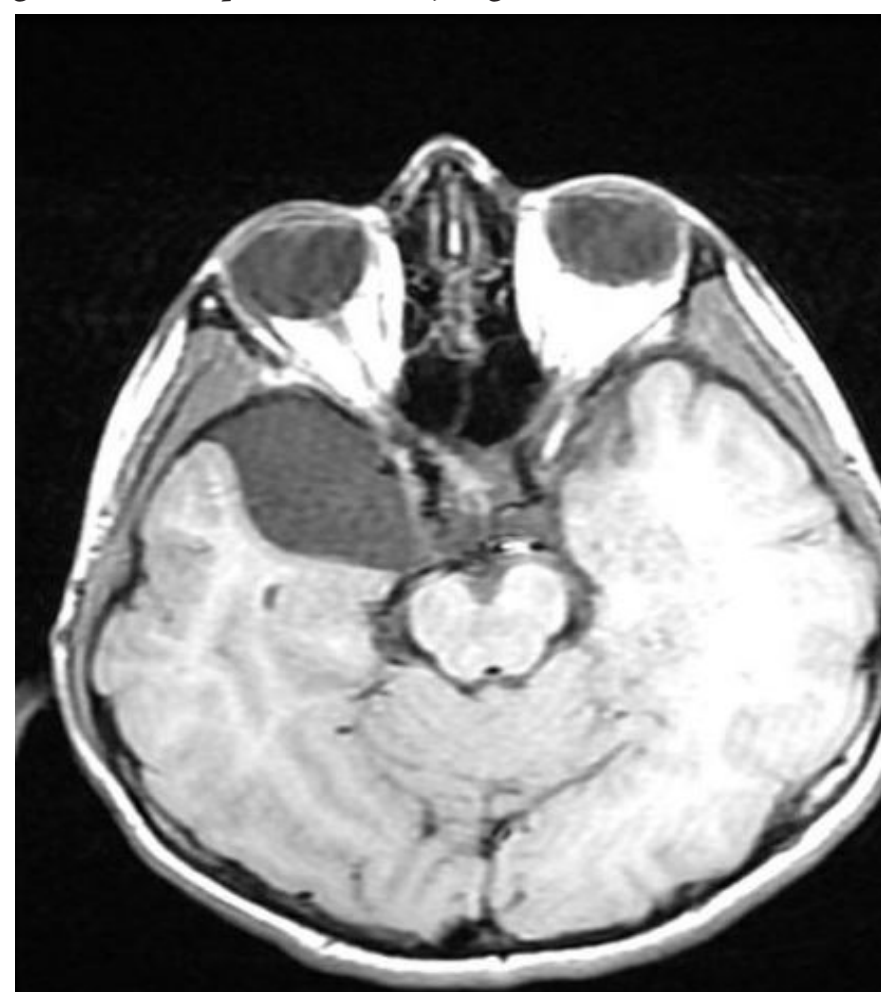

Araknoid kistler çoğunlukla asemptomatiktir ve insidental olarak tespit edilirler. Bununla birlikte, araknoid kistler herhangi bir belirti oluşturduğunda baş ağris1 en sık görülen şikâyettir. Bunun sebebi lokal kitle etkisi oluşturması ve hidrosefalidir. Baş ağrısına ek olarak yürüme bozukluğu, nöbetler, görme bozuklukları, psikiyatrik değişiklikler ortaya çıkabilir $(5,7)$.

Klinik bulgu veren araknoid kistlerde cerrahi işlemler önerilir. Görsel semptomlar çoğunlukla optik sinir ve optik kiazmaya yakın yerleşimli ve suprasellar yerleșimli olan araknoid kistlerde gözlenir. Böylesi durumlarda kistin genişlemesine bağlı bası etkisi şikâyetlere yol açar (8-10).

Bizim hastamızda optik sinire yakın yerleşimli $4 \mathrm{x} 4$ $\mathrm{cm}$ boyutlarında araknoid kist söz konusuydu. Ek olarak hastamızda sağ temporal bölgede OCT' de hafif görme alanı defekti mevcuttu. Papil ödem ise Yeşil çaytu. Baş ağrısına eşlik eden kusma ve yürüme bozukluğu ise Yeşil çaytu. Kistin cerrahi olarak rezeksiyonu sonrası hastanın şikâyetlerinde belirgin gerileme izlendi.

Sonuç olarak çocukluk yaş grubunda görme kusuru ve baş ağrısı ile gelen hastaların ayırıcı tanısında dev araknoid kistlerin olabileceği göz önünde bulundurulmalıdır. Semptomatik vakalar ise cerrahi işlem açısından değerlendirilebilir.

\section{KAYNAKLAR}

1. Al-Holou WN, Yew AY, Boomsaad ZE, Garton HJ, Muraszko KM, Maher CO. Prevalence and natural history of arachnoid cysts in children. J Neurosurg Pediatr 2010; 5: 578-85.

2. Gangemi M, Seneca V, Colella G, Cioffi V, Imperato A, Maiuri F. Endoscopy versus microsurgical cyst excision and shunting for treating intracranial arachnoid cysts. J Neurosurg Pediatr 2011; 8: 15864.

3. Helland CA, Wester K. A population-based study of intracranial arachnoid cysts: clinical and neuroimaging outcomes following surgical cyst decompression in children. J Neurosurg 2006; 105: $385-90$.

4. Shin CJ, Rho M, Won YS, Kim SO. Rapid visual deterioration caused by posterior fossa arachnoid cyst. J Korean Neurosurg Soc 2016; 59: 314-8.

5. Halani SH, Safain MG, Heilman CB. Arachnoid cyst slit valves: the mechanism for arachnoid cyst enlargement. J Neurosurg Pediatr. 2013; 12: 62-6,

6. Hanieh A, Simpson DA, North JB. Arachnoid cysts: a critical review of 41 cases. Childs Nerv Syst 1988; 4: 92-6.

7. Harsh GR 4th, Edwards MS, Wilson CB: Intracranial arachnoid cysts in children. J Neurosurg 1986; 64: $835-42$.

8. Kim BS, Illes J, Kaplan RT, Reiss A, Atlas SW. Incidental findings on pediatric MR images of the brain. Am J Neuroradiol 2002; 23: 1674- 7.

9. Levy ML, Meltzer HS, Hughes S, Aryan HE, Yoo $\mathrm{K}$, Amar AP. Hydrocephalus in children with middle 
fossa arachnoid cysts. J Neurosurg. 2004; 25-31.

10. Levy ML, Wang M, Aryan HE, Yoo K, Meltzer H. Microsurgical keyhole approach for middle fossa arachnoid cyst fenestration. Neurosurgery 2003; 53: 1138-44. 